\title{
Convocatoria de protesta a través de Instagram: análisis socio-cognitivo de estrategias discursivas en el contexto del movimiento social en Chile (2019-2020)
}

\author{
Call for protest through Instagram: a socio-cognitive analysis of \\ discursive strategies in the context of the social movement in Chile \\ (2019-2020)
}

\author{
Mauricio Alarcón Silva. Universidad de La Frontera, Chile \\ m.alarcon11@ufromail.cl \\ $[\mathrm{CV}]$ (1) $\mathrm{R}^{\mathrm{C}} \mathrm{F}$ \\ Camila Cárdenas Neira. Universidad Austral, Chile \\ $[\mathrm{CV}]$ (1) $\mathrm{CR}^{\mathrm{E}} \mathrm{O}$ \\ camila.cardenas@uach.cl
}

El presente trabajo es parte de la tesis doctoral "Estrategias discursivas presentes en la construcción de textos de convocatoria a jornadas de protesta difundidas en redes sociales. Movimiento social en Chile (20192020). Agradecimientos a la Agencia Nacional de Investigación y Desarrollo (ANID), Beca de Doctorado Nacional Folio 21201469, y al Fondo Nacional de Desarrollo Científico y Tecnológico (FONDECYT de Iniciación $N^{\circ} 11200446$ ).

\section{Cómo citar este artículo}

Alarcón, M. y Cárdenas, C. (2021). Convocatoria de protesta a través de Instagram, un análisis socio cognitivo de estrategias discursivas en el contexto del movimiento social en Chile (2019-2020). Revista Latina de Comunicación Social. 79, 127-149. https://www.doi.org/10.4185/RLCS-2021-1524

\begin{abstract}
RESUMEN
Introducción: El artículo presenta resultados preliminares de un estudio piloto enmarcado en una investigación sobre estrategias discursivas empleadas en la construcción de textos de convocatoria a jornadas de protesta, propagadas por redes sociales, en el transcurso de la movilización social en Chile (2019-2020). Desde una dimensión socio-cognitiva, se abordan los recursos ideológicos y metafóricos desplegados discursivamente a través de Instagram, una plataforma emergente en el campo de la comunicación política. Metodología: Con un diseño cualitativo de alcance exploratoriodescriptivo, y a partir de las contribuciones de los Estudios Críticos del Discurso, se analiza un corpus de textos multimodales seleccionados desde una cuenta de base ciudadana con carácter contra-informativo, que durante el estallido social (entre el 18 de octubre de 2019 y 18 de marzo de 2020) contaba con mayor número de seguidores. Resultados: Se identifican categorías que definen el discurso ideológico del movimiento, así como las formas de entender los procesos y actores políticos partícipes del movimiento a partir del uso de ciertas metáforas conceptuales. Discusión y conclusiones: Los resultados, junto con caracterizar una dimensión socio-cognitiva del género
\end{abstract}


convocatoria de protesta, permiten aproximarse a la configuración de unos discursos resistentes que trascienden la mera convocatoria, para articular otros marcos de interpretación colectiva vinculados a los procesos de cambio social. Las categorías discursivas analizadas relevan la persistencia de una lucha callejera y solidaria, que posiciona al movimiento como un actor clave en el escenario político.

PALABRAS CLAVE: estrategia discursiva: comunicación política; ideología; metáfora; movimientos sociales; Instagram; protesta.

\begin{abstract}
Introduction: The article presents preliminary results of a pilot study framed in an investigation on the discursive strategies employed in the construction of texts calling for protest sessions, propagated through social media, during the social mobilization in Chile (2019-2020). From a socio-cognitive dimension, the ideological and metaphorical resources discursively deployed through Instagram, an emerging platform in the field of political communication, are addressed. Methodology: With a qualitative design of exploratory-descriptive scope, and from the contributions of Critical Discourse Studies, a corpus of multimodal texts is analyzed, selected from a citizen-based account, of counterinformative character, which during the social outbreak (between October 18, 2019, and March 18, 2020), had a greater number of followers. Results: The categories that define the ideological discourse of the movement are identified, as well as the ways of understanding the political processes and actors participating in the movement based on the use of certain conceptual metaphors. Discussion and conclusions: The results, together with characterizing a socio-cognitive dimension of the protest call genre, allow an approach to the configuration of resistant discourses that transcend the mere call, to articulate other frameworks of collective interpretation linked to the processes of social change. The discursive categories analyzed reveal the persistence of a solidarity and street struggle, which positions the movement as a key actor in the political scenario.
\end{abstract}

KEYWORDS: discursive strategy; political communication; ideology; metaphor; social movements; Instagram; protest.

\title{
CONTENTS
}

1. Introducción 1.1. Movimientos sociales y protesta 1.2. Comunicación y movimientos sociales 1.3. Instagram y comunicación política 1.4. Textos y estrategias discursivas 1.5. Enfoque socio-cognitivo 1.5.1. Discurso e ideología 1.5.2. Discurso y metáforas 2. Objetivos y supuestos 3. Metodología 4. Resultados 4.1. Esquema Ideológico 4.2. Metáforas conceptuales 5. Discusión y conclusiones. 6. Referencias.

\section{Introducción}

El movimiento ciudadano que se articula tras el denominado estallido social en Chile (2019-2020) se ha constituido en el actor político más relevante de los últimos años. Si bien sus causas y demandas son heterogéneas, existe un factor común que determina su surgimiento como son las políticas neoliberales cimentadas desde la dictadura militar (1973-1990), y sus impactos en la reproducción de la desigualdad social (Aste, 2020; Güell, 2019; Somma, et al., 2020a). Las manifestaciones que se gatillan el 18 de octubre de 2019 también suponen una culminación respecto de otras movilizaciones sociales precedentes, como aquellas lideradas por las y los estudiantes en 2011 (Cuadra, 2020), que van operando un cambio socio-cognitivo en relación con las lógicas de mercantilización y privatización de bienes y derechos fundamentales que pasan a ser intolerables para la población (Cárdenas-Neira y Pérez-Arredondo, 2021). 
Así, el despliegue de la acción colectiva de este movimiento evidencia no solo la capacidad de instalar marcos asociados a un diagnóstico ampliamente compartido, sino, además, de legitimar el repertorio de acción requerido para generar las condiciones político-culturales necesarias a la hora de promover un proceso de transformación social estructural. Dicho repertorio destaca por converger en y apropiarse de los espacios urbanos y digitales para coordinar, ejecutar y propagar tácticas de contención y contestación de diversa índole, entre las que se encuentran concentraciones, marchas, ocupaciones, performances, intervenciones artísticas, cacerolazos, barricadas, saqueos e incendios.

En este contexto, la convocatoria a jornadas de protesta asume un rol específico en el entramado comunicativo del movimiento social. Su potencial, en tanto género desplegado por el movimiento a través de las redes sociales, da cuenta de la producción de significados compartidos por una comunidad retórica de discurso, que a la vez es dinámica y está en permanente construcción. Este género discursivo implica un ejercicio comunicativo de alta complejidad que vincula, de un lado, al grupo enunciador, es decir, organizaciones o agrupaciones de base o con trayectoria política sin representación partidaria ni líderes formales (Somma et al., 2020a), sobre quienes recae la fuerza subjetivadora que impulsa a la acción de protesta (Alarcón y Godoy, 2020), y, de otro lado, al grupo enunciatario, a saber, personas comunes y corrientes que se hallaban pasivas y conformes, pero que tras el estallido social adhieren a exigencias transversales que les motivan a participar masivamente, en quienes reside la agencia movilizadora.

En tal sentido, el género de convocatoria, en coherencia con el enfoque socio-cognitivo desarrollado por van Dijk (2016a), se erige como una instancia mediadora entre la dimensión cognitiva de los individuos y la dimensión social del discurso. Desde esta perspectiva, el presente estudio se propone caracterizar las estrategias discursivas empleadas para llamar a protestar, así como a establecer una posición ideológica del movimiento social frente al destinatario interpelado: la ciudadanía en su conjunto, por una parte, y el poder político y económico, por la otra. En particular, adoptando este enfoque socio-cognitivo se efectúa una aproximación a los textos de convocatoria a jornadas de protesta, con la cual se pone énfasis en la construcción de marcos cognitivos a partir del uso de metáforas conceptuales.

El corpus se conforma por textos seleccionados desde una cuenta de Instagram, cuyo uso, a diferencia de otras redes sociales como Twitter y Facebook, es emergente en el ámbito de la comunicación política, al punto de que se plantea un desaprovechamiento cualitativo y cuantitativo de las posibilidades que ofrece esta plataforma (Selva-Ruiz y Caro-Castaño, 2017). Según la literatura consultada, la mayoría de las investigaciones referidas al uso político de Instagram se orienta tanto a las estrategias de humanización de figuras públicas (Lalancette \& Raynauld, 2017; Quevedo-Redondo y Portalés-Oliva, 2017; Sampietro y Sánchez-Castillo, 2020), como a las estrategias de posicionamiento de líderes, partidos y candidatos en campaña (Aladro-Vico y Requeijo-Rey, 2020; Muñoz \& Towner, 2017; Slimovich, 2019), pero aún son escasas aquellas dedicadas al análisis de activistas cuyas cuentas promueven causas sociales (Acosta, 2020; Fernández, 2019; Gómez, Simioni y Traktman, 2021) y, en especial, de grupos autogestionados cuyas cuentas combinan finalidades de movilización y contra-información (Alarcón y Godoy, 2020). El estudio propuesto busca hacer una contribución para acortar esta brecha de conocimiento.

A partir del análisis crítico del discurso aplicado a una muestra de 33 afiches de convocatoria, se abordan los recursos ideológicos y metafóricos identificados en las publicaciones de la cuenta @ capucha_informa de Instagram, entre el 18 de octubre de 2019 y el 18 de marzo de 2020. Para dar sustento teórico a este análisis, a continuación se exponen cinco ejes temáticos relativos a la delimitación conceptual de los movimientos sociales y sus acciones de protesta, sus prácticas comunicativas mediadas por redes sociales, las estrategias de comunicación política desarrolladas en 
plataformas como Instagram, las estrategias discursivas empleadas en la producción de textos de convocatoria, y la dimensión socio-cognitiva de dichas estrategias en sus niveles ideológico y metafórico. Más tarde se revisan los objetivos y supuestos de investigación y se describe la metodología utilizada. Finalmente, se reportan los resultados que se desprenden de ambos niveles de análisis, con su respectiva discusión y conclusiones.

\subsection{Movimientos sociales y protesta}

Charles Tilly (1979) circunscribe a los movimientos sociales como formas específicas de contienda política, que ponen en juego intereses de diversos grupos, definiéndolos como:

una prolongada serie de interacciones entre quienes ostentan el poder y personas que reclaman con éxito hablar en nombre de sectores que carecen de representación formal, en el curso de la cual esas personas hacen públicamente visibles demandas de cambios en la distribución o ejercicio del poder, y justifican esas demandas con manifestaciones públicas de apoyo (p. 12).

Este autor hace hincapié en el rol de la interacción comunicativa, subrayando la mediación de mecanismos de presión - que luego denominará repertorio de acción (Tilly, 1979)- para activar procesos de cambio social a favor de un colectivo que justifica su demanda a través del apoyo público. Lo esencial de su propuesta no son los elementos aislados que componen la definición, sino su integración y articulación:

(1) campañas de reivindicación colectivas contra las autoridades afectadas; (2) un abanico de actuaciones para llevar a cabo esas reivindicaciones que incluyen a asociaciones con un fin específico, concentraciones públicas, declaraciones en los medios y manifestaciones; (3) manifestaciones públicas del valor de la unidad, el número y el compromiso de la causa (Tilly y Wood, 2009, p. 28).

Por su parte, Della Porta y Diani (2011) definen los movimientos sociales como "procesos sociales diferenciados consistentemente en mecanismos a través de los cuales los actores comprometidos en la acción colectiva se involucran en relaciones conflictivas con oponentes claramente identificados, se vinculan en densas redes informales; y comparten una identidad colectiva diferenciada" (p. 43). Desde un punto de vista descriptivo, el foco está puesto en la configuración de un actor colectivo que se posiciona en el debate político a partir de la adhesión a ciertos principios o valores en disputa, que incitan al apoyo o la discrepancia frente a la posibilidad de cambio social. La acción colectiva coordinada del movimiento social se distingue de otras formaciones similares por el compromiso al momento de buscar estrategias para cumplir un fin común, sin afectar la autonomía e independencia de los involucrados, pero al mismo tiempo generando un sentido de identidad que trasciende el desarrollo de acciones puntuales de protesta.

En lo que refiere a la protesta, si bien no es exclusiva de los movimientos sociales, se ha considerado como una forma típica de estos (Della Porta y Diani, 2011). Según estos autores, consiste en una "expansión de los repertorios de participación política" (p. 216) que dispone de canales indirectos de persuasión para influir en quienes toman las decisiones. Las formas que adopta la acción colectiva o los repertorios de acción corresponden al "conjunto de medios que tiene [un grupo] para plantear reivindicaciones diferentes a individuos diferentes" (p. 218), tales como boicots, ocupaciones, concentraciones, barricadas, entre otras. En la elección del repertorio de acción inciden diversos factores, los cuales se conectan con aspectos culturales y valóricos de los activistas, por tanto, no solo está en juego la eficacia de la acción como factor decisivo, sino que aspectos emocionales vinculados con su significación y valor simbólico. 


\subsection{Comunicación y movimientos sociales}

En cuanto a las relaciones comunicativas de poder implicadas en la emergencia de los movimientos sociales, Castells $(2009,2012)$ postula que estos surgen en momentos de crisis política, económica y social, desencadenados por una situación política específica o el deterioro de esta. Esto sucede en un contexto de pérdida del control de los mensajes de los colectivos políticos tradicionales, pasando a una red de mensajes autónomos con capacidad para movilizar la acción política, esto es, la "auto comunicación de masas" (Castells, 2009, p. 25) generada por el uso de internet y redes sociales, entendidas como herramientas que facilitan la participación, de un lado, y como escenarios imprescindibles para el cambio social (Castells, 2012), del otro.

$\mathrm{Al}$ respecto coexisten diversas posturas referidas al impacto de las redes sociales en las prácticas de comunicación política de los movimientos sociales: desde aquellas que enfatizan el rol de la hipermediación (Scolari, 2008) como espacio de socialización de mensajes, contenidos y distribución de recursos cognitivos para la movilización social, hasta aquellas que enfatizan un proceso de individualización que desvirtúa la esencia de la acción política (Córdoba-Hernández, 2020). No obstante, las distintas posturas parecen coincidir en que si bien el intercambio de contenidos a través de los medios digitales crea una oportunidad para personalizar la acción colectiva, esta favorece, mediante las redes sociales, la autoorganización del movimiento o "acción conectiva" (Bennett \& Segerberg, 2012, p. 743).

\subsection{Instagram y comunicación política}

Existe abundante bibliografía referida al uso de redes sociales en el ámbito de la comunicación política (Bennett \& Segerberg, 2016; Della Porta \& Pavan, 2018; Gerbaudo \& Treré, 2015). Sin embargo, tal como constatan Selva-Ruiz y Caro-Castaño (2017), gran parte de estos trabajos se concentra en plataformas como Twitter y Facebook, relegando otras plataformas de popularidad reciente. A pesar del crecimiento de Instagram, que el año 2020 llega a un total de mil millones de usuarios a nivel mundial, la producción académica de estudios sobre el rendimiento y los alcances de este medio como parte de una estrategia de comunicación política continúa siendo escasa (MarcosGarcía et al., 2020).

En efecto, en los últimos cinco años Instagram se ha convertido en objeto de estudio en el campo de las ciencias sociales, en relación con una serie de áreas temáticas que abarcan, entre otras, los usos educativos por parte de adolescentes y jóvenes, los efectos psicológicos y emocionales en la salud mental, el impacto social en la conformación de públicos y perfiles de usuarios, el posicionamiento comercial de empresas y marcas, la emergencia de influencers y bloggers como generadores de contenidos y publicidad, y la proliferación de estrategias de propaganda y comunicación política (Figuereo-Benítez et al., 2021). En lo que respecta a esta última área, se han estudiado mayoritariamente los usos que líderes, partidos y candidatos dan a esta red social para autopromocionarse y mejorar su imagen profesional y humana, pero se ha indagado menos en torno a cómo las y los ciudadanos corrientes critican a estos actores y muestran su descontento hacia la política tradicional (Marcos-García, 2018).

Adicionalmente, son incipientes las investigaciones que ahondan en las estrategias comunicativas desplegadas por movimientos sociales y colectivos de base ciudadana para reaccionar ya sea a conflictos históricos o a coyunturas socio-políticas determinadas. Algunos ejemplos se vinculan a las campañas feministas por la igualdad de género (Fernández, 2019) o el derecho al aborto libre 
(Acosta, 2020), las luchas de pueblos indígenas por el reconocimiento de sus formas de resistencia territorial y sus cosmologías (Cardoso Franco y Da Silva, 2020), o el activismo medioambiental que aboga por la armonización de las acciones humanas con un orden cósmico, social y personal (Ardèvol et al., 2021).

Siguiendo a Pont Sorribes (2020), la eficacia de Instagram en el ámbito de la comunicación política reside en el poderío que ostentan las imágenes para posicionar relatos con los que consolidar a líderes y partidos ya establecidos, pero también para dar tribuna a nuevos agentes de cambio en la esfera pública digital. En concordancia con ello, Herrera y Codina (2015) clasifican a Instagram como una red social visual, señalando que "las redes sociales visuales son aquellas que sirven como plataforma y generan comunidad en base a compartir imágenes. Estas imágenes pueden ser estáticas, como fotografías o gráficos, o en movimiento, como vídeos o animaciones" (p. 4). Como indican Quevedo-Redondo y Portalés-Oliva (2017), "dentro del universo online, la red social Instagram constituye una de las principales apuestas por un modelo comunicativo basado en el poder de denotación de las fotografías y en la emergencia de un tipo de conversación basada en retratos, selfies y vídeos" (p. 917).

Ahora bien, sin desatender esta impronta visual, lo cierto es que Instagram se aboca a la elaboración y la diseminación de diseños o artefactos multimodales que combinan dos o más modos semióticos (Kress, 2010), como es el caso de los memes que conjugan fotografías, enunciados escritos y emoticonos, o de los reels que añaden imágenes en movimiento y música. Estos recursos expresivos, a pesar de estar ampliamente disponibles y de ser manipulados con naturalidad por parte de los usuarios, no reciben el mismo tratamiento cuando son empleados con finalidades contenciosas en escenarios de protesta social. En estos casos, tales recursos se ensamblan en diseños o artefactos para cumplir otra gama de funciones, tales como movilizar, denunciar, conmemorar y argumentar (Cárdenas-Neira, 2018). En esta dirección, el análisis del discurso multimodal permite averiguar la manera en que las ideologías se realizan en los textos (Cárcamo, 2018) y, en concreto, cómo se configuran estrategias de polarización ideológica entre los actores movilizados y sus adversarios políticos.

\subsection{Textos y estrategias discursivas}

Abordar los movimientos sociales desde su producción discursiva contextualizada en el extenso campo de la comunicación política, supone una aproximación a procesos de interacción que incluyen "la continua interpretación de intenciones expresadas verbal y no verbalmente, de forma directa, indirecta o velada" (Calsamiglia y Tusón, 2019, p. 2). Asimismo, complejas relaciones de poder, solidaridad, dominación o resistencia se entrecruzan en la formación de los discursos del propio movimiento.

Como actor político, el movimiento asume un rol de enunciador, que en el proceso de enunciación permite la materialidad de un producto concreto, el enunciado, unidad básica que puede adoptar múltiples formas en el marco de un intercambio comunicativo con un destinatario enunciatario. Al combinar estos enunciados se da lugar a la formación de textos, como unidades comunicativas intencionales y completas, cuyo significado y sentido puede ser abordado desde el análisis discursivo (Calsamiglia y Tusón, 2012, pp. 3-4), en general, y desde el análisis multimodal, en particular (Martín Menéndez, 2012). En este punto, el potencial multimodal de la unidad textual radica en la posibilidad de presentarse en diversos modos semióticos, tales como lenguaje escrito, imagen, gestualidad, sonido, música, entre otros. 
A la luz de este enfoque analítico, los textos de convocatoria a jornadas de protesta constituyen eventos comunicativos que entrañan tanto una finalidad comunicativa por parte de un enunciador, como el procedimiento utilizado para alcanzarla. Este procedimiento corresponde a la estrategia discursiva, es decir, un plan llevado a cabo por el hablante según la situación específica de interacción en la que se encuentra, el cual se conformaría por la conjugación de recursos gramaticales y pragmáticos (Martín Menéndez, 2000). Sal Paz Maldonado (2009) subraya la intencionalidad del enunciador para incrementar la efectividad comunicativa, mediante el uso sistemático de procedimientos lingüísticos y extralingüísticos, incluyendo así otros recursos multimodales.

La identificación de elementos regulares en términos de contenido y de forma apunta a la noción de género discursivo (Bajtín, 2005), definido "a partir de la intersección de un conjunto de estrategias discursivas recurrentes y un conjunto de rasgos culturales dominantes. Esto supone que determinados conjuntos de estrategias son esperables en determinados géneros" (Martín Menéndez, 2009, p. 3). Ahondar en las características de los textos de convocatoria, en cuanto género discursivo seleccionado por el movimiento social para cumplir sus finalidades comunicativas, proporciona información relevante sobre la cultura de protesta que le es distintiva (Cárdenas-Neira, 2018), en tanto permite desvelar los procesos socio-cognitivos involucrados en la creación y distribución de sus mensajes, así como también en el papel que estos desempeñan para proyectar su efectividad ante una audiencia dada.

\subsection{Enfoque socio-cognitivo}

Siguiendo a van Dijk (2006), el enfoque socio-cognitivo integra las representaciones y los procesos mentales referidos a la construcción y la negociación de sistemas de creencias compartidas socialmente. Tales creencias pueden ser comprendidas a partir de las funciones sociales asignadas por un grupo y sus miembros, y se clasifican en dos tipos: fácticas, consensuadas como conocimiento validado al interior de comunidades epistémicas (van Dijk, 2016b), y evaluativas, asumidas como opiniones personales, actitudes e ideologías que tienen en común colectivos de carácter diverso (van Dijk, 1999). Los textos creados y difundidos por los movimientos sociales, comunicados a partir de los géneros discursivos que seleccionan para promover sus causas y demandas, sintetizan y amplifican dichas creencias para dar cumplimiento a objetivos contenciosos variados. Y, en esta dirección, son las creencias evaluativas las que obtienen mayor impacto en la comunicación política de estos movimientos.

\subsubsection{Discurso e ideología}

El discurso supone un componente socio-cognitivo que, como se ha dicho, está a la base de su propia estructura y de las formas de interacción que propicia en la sociedad. De lo anterior se desprende que la especificidad del discurso político estaría dada por la mediación entre las prácticas sociales y la ideología "que define la identidad de un grupo y, por consiguiente, los sentimientos subjetivos de la identidad social" (van Dijk, 2003, p. 28). Como señala van Dijk (2003, 2005), la ideología no aborda cualquier tipo de creencias, sino aquellas más básicas o axiomáticas a partir de las cuales se da coherencia al actuar de las personas, mediante opiniones o actitudes, por ejemplo, respecto al origen de la vida, al rol del hombre o la mujer o, como es el caso del presente estudio, el modelo económico o socio-político más adecuado desde el punto de vista del movimiento social.

Para deducir la estructura del discurso ideológico, van Dijk (2003) propone un esquema asociado a la identidad del grupo, que incluye los "criterios de pertinencia, actividades, objetivos, normas, relaciones con los demás, y recursos" (p. 57). En tanto estructura organizativa de las creencias 
ideológicas, los componentes de este esquema ostentan una función cognitiva anclada en la estructura social: "parecen ser las coordenadas fundamentales de los grupos sociales y las condiciones de su existencia y reproducción" (van Dijk, 2006, p. 96). Asimismo, estos componentes articulan la oposición entre grupos y sustentan sus luchas materiales y simbólicas. Dichas creencias ideológicas se expresan mediante diferentes estrategias discursivas, entre las cuales destaca la formulación de metáforas.

\subsubsection{Discurso y metáforas}

Según Lakoff y Johnson (1986), las metáforas no solo son recursos retóricos del lenguaje, sino que, sobre todo, son figuras de pensamiento que impregnan los diversos ámbitos de acción y cognición de la vida diaria. En consecuencia, la metáfora es entendida como un fenómeno cognitivo, en el que un objeto de conocimiento es representado conceptualmente en términos de otro. Como explica Lizcano (2002), "un ámbito que era desconocido o mal conocido puede así empezar a conocerse -a 'hacerse una idea'- mediante la luz que sobre él arrojan los conocimientos ya elaborados para otro ámbito diferente, sean estos conocimientos implícitos o explícitos" (p. 35).

Por lo tanto, es posible comprender y experimentar un fenómeno abstracto (dominio de destino: A) gracias a un dominio más concreto (dominio fuente: B) que constituye el origen del concepto importado. Esto se traduce en la clásica fórmula A ES B, la cual se sostiene en un conjunto de correspondencias que existe entre ambos términos. De este modo, comprender una metáfora conceptual implica conocer ese conjunto de correspondencias. En palabras de Kövecses (2010), "hay un conjunto de correspondencias sistemáticas entre [el dominio] fuente y el [dominio de] destino en el sentido de que los elementos conceptuales constituyentes de B corresponden a elementos constituyentes de A. Técnicamente, estas correspondencias conceptuales son a menudo referidas como mapeos [traducción propia]" (p. 7).

Para Lakoff y Johnson (1986), la experiencia cotidiana aporta elementos cognitivos útiles para interpretar fenómenos más complejos, no obstante, el traspaso de dichos elementos cognitivos no posee una precisión absoluta, pues no hay control respecto de la totalidad de las posibilidades interpretativas que brinda el dominio fuente, debido a que estas posibilidades se reconstruyen a partir del conocimiento contextual compartido cultural, histórica y socialmente. En palabras de estos autores, "cuando decimos que un concepto está estructurado por una metáfora, queremos decir que está parcialmente estructurado y que puede ser extendido de ciertas maneras, pero no de otras" (p. 45). En consecuencia, la metáfora tiene implicancias en la selección de los énfasis o atributos dados al dominio de destino, al tiempo que, mediante un proceso de enmarcado metafórico, se dejan fuera otros énfasis o atributos.

En esta misma línea, Lizcano (2002) explica el carácter asimétrico presente en la relación entre dominios fuente y de destino. Esto lo ejemplifica con la metáfora el "atardecer de la vida", un fenómeno astronómico, pero de comprensión cotidiana como el ciclo del día, en particular el ocaso de este (atardecer), lo cual permite entender una etapa del ciclo de la vida como es la vejez. Con esta metáfora el ciclo vital es astronomizado. Sin embargo, la operación se dificulta si se realiza un ejercicio inverso, atribuir el significado del ciclo vital para explicar algo cotidiano como es el día y la noche: "la vejez del día". Es el denominado principio de unidireccionalidad descrito por Kövecses (2010), que va desde la experiencia concreta a la comprensión más abstracta. 


\section{Objetivos y supuestos}

El presente trabajo corresponde a un estudio piloto enmarcado en el desarrollo de la tesis doctoral, la cual se propone como objetivo general analizar las estrategias discursivas empleadas por el movimiento social en Chile (2019-2020) para construir textos de convocatoria a jornadas de protesta difundidas en redes sociales. Como objetivos específicos, este estudio busca:

- Caracterizar, desde un enfoque socio-cognitivo, el uso del esquema ideológico como estrategia discusiva presente en los textos de convocatoria a jornadas de protesta del movimiento social en Chile (2019-2020).

- Caracterizar, desde un enfoque socio-cognitivo, el uso de la metáfora conceptual como estrategia discusiva presente en los textos de convocatoria a jornadas de protesta del movimiento social en Chile (2019-2020).

Sobre la base de los objetivos formulados, se asumen los siguientes supuestos de investigación:

- Los textos de convocatoria a jornadas de protesta producidos por el movimiento social (2019-2020) y publicados en redes sociales como Instagram, poseen características que permiten identificarlos como un género discursivo específico, diferenciado de otros géneros propios del movimiento social, como declaraciones, manifiestos, comunicados, etc.

- Las estrategias discursivas empleadas por el movimiento social para construir textos de convocatoria a jornadas de protesta impactan no solo en la conformación de una identidad y unas creencias ideológicas distintivas del movimiento, sino que en la configuración de unos discursos resistentes o contra-discursos que trascienden la mera convocatoria, para articular otras acciones y marcos de interpretación colectiva vinculados a los procesos de cambio social.

\section{Metodología}

Este estudio adopta un enfoque cualitativo de alcance exploratorio-descriptivo. Desde los Estudios Críticos del Discurso, se asume que las relaciones entre producción textual, prácticas discursivas y prácticas sociales entrañan diversas formas de dominación o resistencia que pueden ser desveladas a través del análisis (van Dijk, 2016a), de tal manera que esta premisa orienta el examen del corpus obtenido. En esta dirección, la selección de unidades textuales de sentido, cuyo propósito comunicativo es convocar a jornadas de protesta, busca "explorar ciertas características o categorías para una posterior recolección más amplia y robusta [del corpus]” (Parodi, 2010, p. 27).

Para recopilar las publicaciones analizadas se optó por una red social emergente en el campo de la comunicación política, como es la plataforma Instagram, que sobresale por su inmediatez y por la presencia simultánea de los modos visual y escrito. Instagram muestra el más alto crecimiento en Chile durante los últimos años, según el reporte We Are Social \& Hootsuite (2021), alcanzando los 9,8 millones de usuarios. En concreto, se observó un conjunto de cuentas creadas al inicio del estallido social que, de un lado, aprovecharan las posibilidades de diseño y difusión de contenidos digitales, y del otro, destacaran por tener una base ciudadana y dedicarse a la contra-información. De las cuentas consideradas se priorizó para este estudio la de @capucha_informa, pues concentraba el mayor número de seguidores a marzo de 2020 (sobre los 154 mil), configurándose así un estudio de caso único (Yin, 2014).

El corpus emanado de @capucha_informa asciende a 371 publicaciones recolectadas de forma manual, las cuales fueron clasificadas y organizadas inicialmente para distinguir las acciones colectivas del repertorio de protesta del movimiento social, así como los ejes temáticos principales de las convocatorias. Los criterios que guiaron la selección de estas publicaciones fueron los siguientes: 
- Textos multimodales: combinación imagen - texto escrito.

- Convocatoria a protesta: publicaciones referidas al estallido social.

- Convocantes: colectivos de base ciudadana.

- Temporalidad: entre el 18 de octubre de 2019 y el 18 de marzo de 2020.

Para llevar a cabo el presente estudio piloto se conformó un subcorpus que representa en torno al 10\% del corpus mayor (33 publicaciones), con el propósito de probar una matriz de análisis crítico del discurso elaborada de manera ad hoc para los efectos de la investigación doctoral. Algunos lineamientos contemplados para la elaboración de esta matriz se desprenden del trabajo de CárdenasNeira (2018), quien realiza un análisis crítico multimodal de textos de protesta publicados en Facebook durante las movilizaciones estudiantiles en Chile (2011-2013).

Este artículo reporta resultados del estudio piloto, los cuales se derivan del análisis de solo una de las tres dimensiones que abarca dicha matriz (ver Tabla 1), dejando fuera las dimensiones enunciativa y socio-semiótica. Desde un enfoque socio-cognitivo, se abordaron las 33 publicaciones del subcorpus a partir de categorías y subcategorías que comprenden dos niveles de análisis crítico del discurso: esquema ideológico y metáfora conceptual. A su vez, dicho análisis manual resultó apoyado por el software ATLAS.ti 9.0, con el cual se generaron figuras en las que se sintetizan los principales hallazgos. En la exposición de tales hallazgos se emplean 12 de las publicaciones más significativas del conjunto, para ejemplificar sus alcances y resguardar la extensión de este trabajo.

Tabla 1. Matriz de análisis dimensión socio-cognitiva

\begin{tabular}{|c|c|c|}
\hline Categorías de análisis & Definición & Subcategorías \\
\hline $\begin{array}{l}\text { Esquema ideológico } \\
\text { (van Dijk, 2003). }\end{array}$ & $\begin{array}{l}\text { Categorías básicas de } \\
\text { organización de la vida e } \\
\text { identidad de un grupo, las cuales } \\
\text { permiten que los actores sociales } \\
\text { comprendan, construyan, } \\
\text { rechacen o modifiquen } \\
\text { rápidamente una ideología. }\end{array}$ & $\begin{array}{l}\text { Polarización: endogrupo (nosotros) / exogrupo (ellos). } \\
\text { Descripción: autorrepresentación positiva (nosotros) / } \\
\text { heterorrepresentación negativa (otros). } \\
\text { Identificación: criterios de pertenencia. } \\
\text { Intereses: justificación de fines. } \\
\text { Actividad: qué hacen sus miembros. } \\
\text { Normas y valores: deber ser; evaluación moral. }\end{array}$ \\
\hline $\begin{array}{lr}\text { Metáfora } & \text { conceptual } \\
\text { (Kövecses, } & 2010 ; \\
\text { Lakoff y } & \text { Johnson, } \\
1986) .\end{array}$ & $\begin{array}{l}\text { Fenómeno cognitivo en el que un } \\
\text { objeto de conocimiento es } \\
\text { representado conceptualmente en } \\
\text { términos de otro. }\end{array}$ & $\begin{array}{l}\text { Dominios fuente y dominios de destino: según la } \\
\text { fórmula A ES B. } \\
\text { Metáforas orientacionales: organizan un sistema } \\
\text { global de conceptos con relación a otro sistema, } \\
\text { sustentándose en la experiencia física de nuestra } \\
\text { ubicación espacial (p. ej.: MÁS ES ARRIBA, } \\
\text { "subieron las ventas"; MENOS ES ABAJO; } \\
\text { "decayeron los ánimos"). } \\
\text { Metáforas ontológicas: asumen que nuestra } \\
\text { experiencia de los objetos físicos y de las sustancias } \\
\text { proporciona una base adicional para la comprensión de } \\
\text { vivencias, actividades, motivaciones, etc. (p. ej.: LA } \\
\text { MENTE ES UNA MÁQUINA, "se le salió un } \\
\text { tornillo"). } \\
\text { Metáforas estructurales: involucran casos en los que } \\
\text { un concepto está estructurado metafóricamente en }\end{array}$ \\
\hline
\end{tabular}




\begin{tabular}{|l|l|l|}
\hline & & $\begin{array}{l}\text { términos de otro concepto (p. ej.: EL TIEMPO ES } \\
\text { DINERO, “el tiempo es oro"). }\end{array}$ \\
\hline
\end{tabular}

Fuente: Elaboración propia

\section{Resultados}

\subsection{Esquema ideológico}

Esta sección reporta el análisis crítico del discurso efectuado a nivel ideológico, cuyos resultados revelan una clara definición de grupos con intereses en oposición, con atributos que varían en función de los ejes temáticos que abordan las convocatorias: trabajo, salud, educación, género y feminismo, derechos humanos, presos políticos y criminalización de la protesta, nueva constitución, etc. Los rasgos de las convocatorias más frecuentes, que responden a actividades típicas como marchas y concentraciones, comparten patrones de polarización, descripción e identificación.

A grandes rasgos, se autorrepresenta positivamente al movimiento social y los segmentos de la población que lo componen (capas empobrecidas o precarizadas por el modelo neoliberal imperante, ciudadanos indignados que reivindican los derechos que les han sido negados, manifestantes que se toman las calles para expresar su descontento, mujeres y otras minorías que se rebelan ante la exclusión y la discriminación, etc.), a quienes se les caracteriza ejecutando acciones heroicas y altruistas (luchar, salvar, denunciar, apoyar, educar, etc.), guiadas por normas y valores análogos (sacrificio, valentía, empatía, solidaridad, sensibilidad, respeto, etc.). Como contraparte, se heterorrepresenta negativamente a aquellos grupos que conservan el poder político, policial y económico (el Estado, gobernantes, fuerzas policiales y militares, empresarios, capas adineradas, etc.), a quienes se les caracteriza ejecutando acciones injustas y reprochables (abusar, vulnerar, dañar, reprimir, violar, etc.), también orientadas por normas y valores equivalentes (indiferencia, avaricia, segregación, ensañamiento, deshumanización, etc.).

La Figura 1 muestra un resumen de la oposición nosotros/ellos observada en un conjunto acotado de ejemplos. En la columna izquierda se aprecia quiénes pertenecen al endogrupo y en la columna derecha a quiénes pertenecen al exogrupo, junto con un enunciado que releva el principal atributo con el que se enmarca su autorrepresentación positiva y heterorrepresentación negativa, respectivamente. 
RLCS, Revista Latina de Comunicación Social, 79, 127-149

[Investigación] DOI: 10.4185/RLCS-2021-1524| ISSN 1138-5820| Año 2021

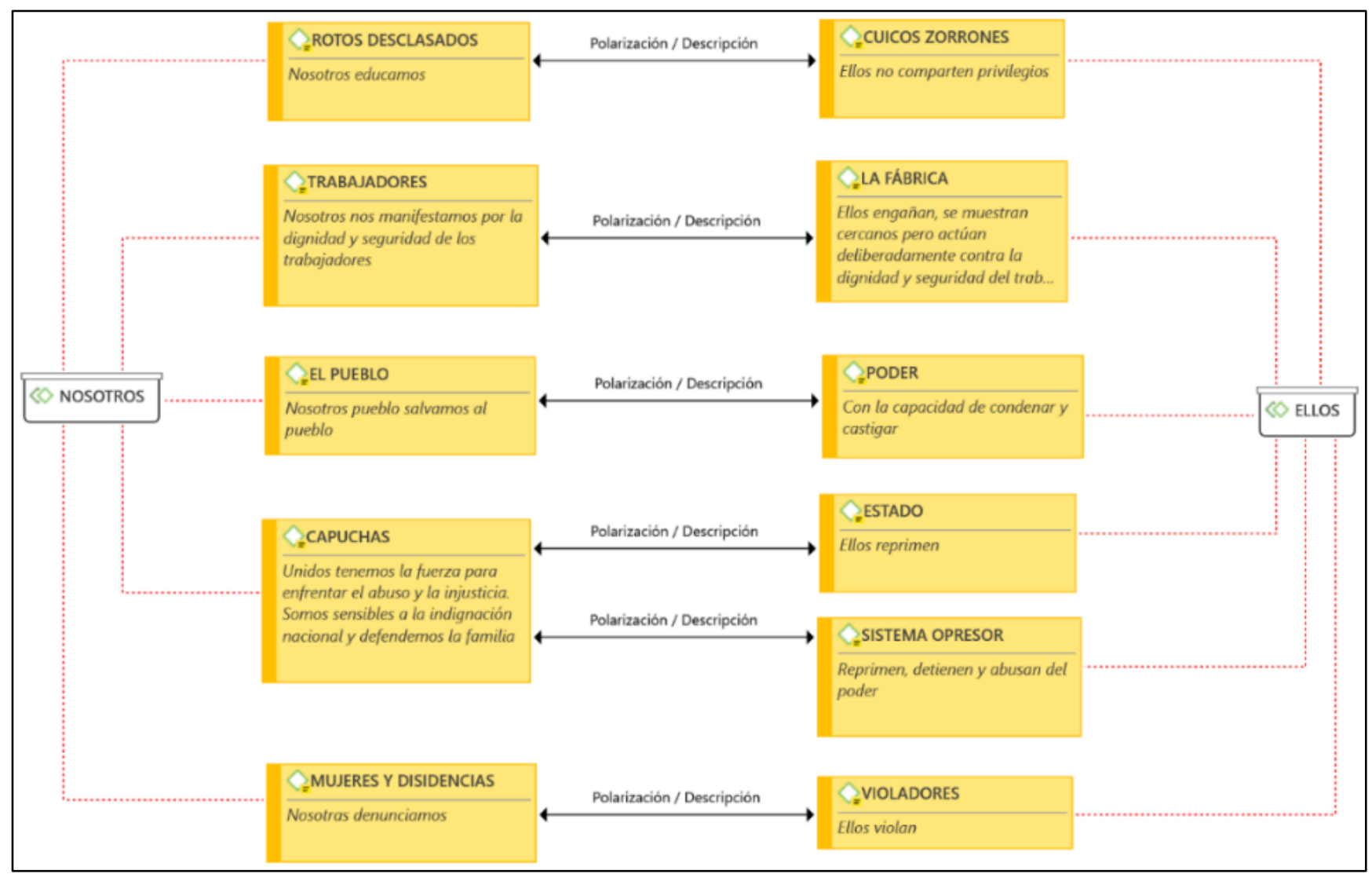

Figura 1. Polarización/Descripción

Fuente. Elaboración propia

Las publicaciones seleccionadas para ilustrar este análisis se muestran a continuación:

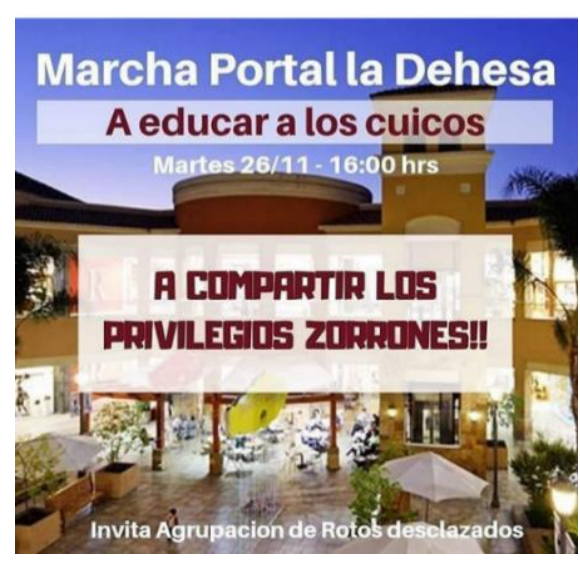

Ejemplo 1: Rotos desclasados Fuente: @ capucha_informa

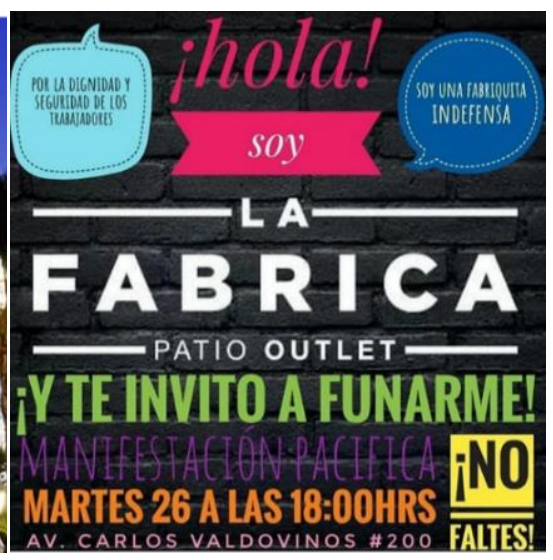

Ejemplo 2: La Fábrica

Fuente: @capucha_informa

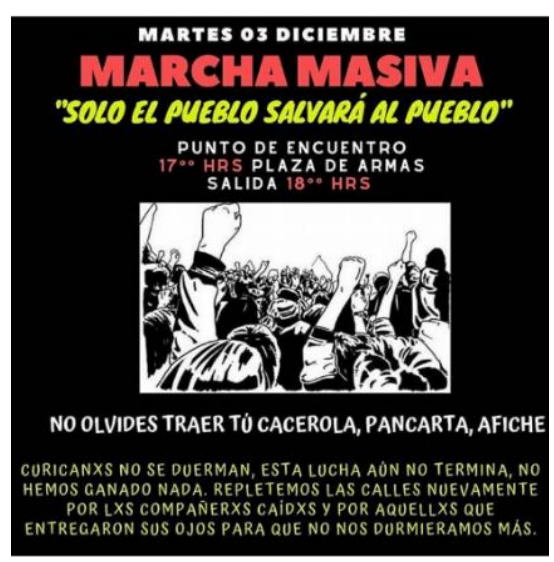

Ejemplo 3: El pueblo

Fuente: @capucha_informa 
RLCS, Revista Latina de Comunicación Social, 79, 127-149

[Investigación] DOI: 10.4185/RLCS-2021-1524| ISSN 1138-5820| Año 2021

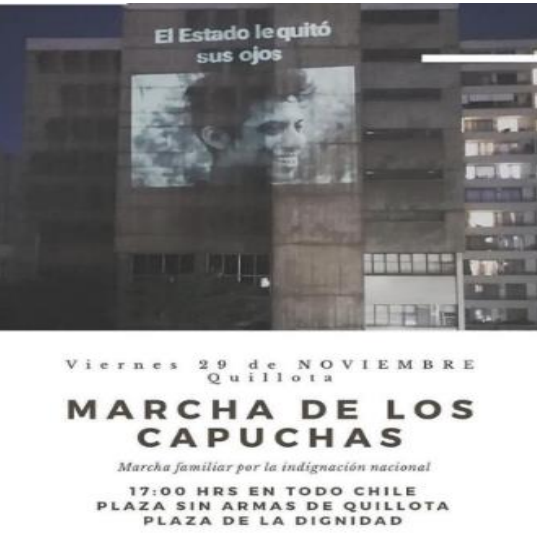

Ejemplo 4: Capuchas 1

Fuente: @capucha_informa

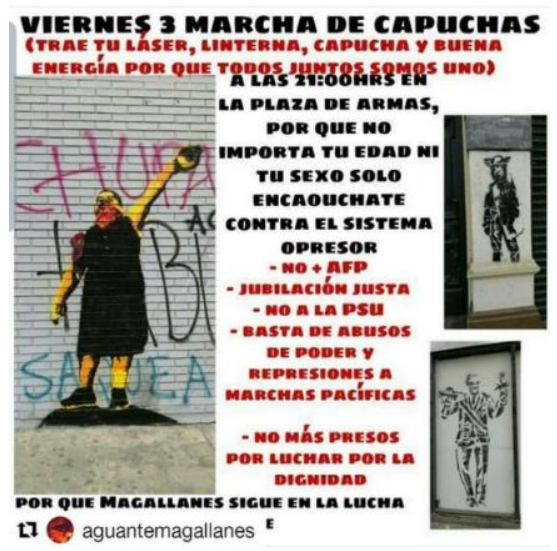

Ejemplo 5: Capuchas 2

Fuente: @capucha_informa

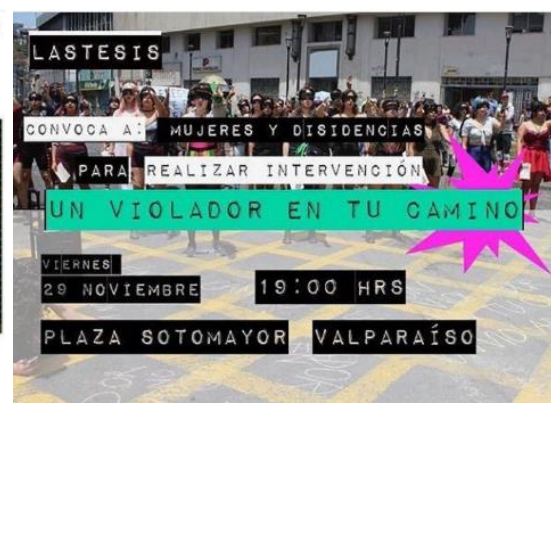

Ejemplo 6: Un violador en tu camino

Fuente: @capucha_informa

En el Ejemplo 1 se establece una POLARIZACIÓN entre los rotos desclasados (pertenecientes a la clase baja y media) y los cuicos zorrones (pertenecientes a la clase alta), a quienes se les pretende educar para que aprendan a compartir sus privilegios. En este caso, el esquema ideológico se complementa con la IDENTIFICACIÓN que da cuenta, por una parte, de un colectivo con conciencia de clase (endogrupo) que lucha por terminar con los abusos de poder que ostenta la clase acomodada y, por otra, de una elite (exogrupo) que es indiferente a la desigualdad social y disfruta de sus privilegios mientras el resto del país se encuentra movilizado. Los INTERESES consisten tanto en evidenciar la mantención de dichos privilegios como en visibilizar la necesidad de acabar con ellos, lo cual se consigue a través de la ACTIVIDAD que corresponde a marchar hacia el Portal La Dehesa -el principal centro comercial de una de las comunas más ricas de la Región Metropolitana-, disrumpiendo con ello la normalidad a la que sus vecinos están acostumbrados. Acometer este tipo de protesta implica NORMAS Y VALORES que inspiran la acción de educar, asociados a la responsabilidad (de quien educa) y a la empatía y la solidaridad (de quienes buscan ser educados).

En una dirección similar, en el Ejemplo 2 se establece una POLARIZACIÓN entre los trabajadores comprometidos con la dignidad y la seguridad de sus pares frente a La Fábrica que, por su parte, representa a los dueños y administradores de este centro comercial. Mientras que en el ejemplo anterior el enunciador del texto de convocatoria es el endogrupo que llama a protestar, en este caso se produce un desdoblamiento discursivo (Bajtín, 2005) con el cual se le asigna al exogrupo el rol de hablante: "soy La Fábrica Patio Outlet y te invito a funarme [sic]". En este contexto, funar equivale a denunciar públicamente a una persona o grupo de personas que ha cometido una acción repudiable, como son los empleadores que han transgredido los derechos de sus empleados. Con estos movimientos retóricos se propone un esquema ideológico parcialmente invertido, en el que la autorrepresentación positiva recae irónicamente en los miembros del exogrupo, si bien ante la audiencia son ellos quienes resultan heterorrepresentados negativamente. De este modo, la IDENTIFICACIÓN concierne, de un lado, a una "fabriquita indefensa" que está a merced de la furia de sus trabajadores y, del otro, a los propios trabajadores que reclaman un mejor trato laboral. En cuanto a los INTERESES, es patente la incongruencia que deriva del uso de la ironía, pues los fines perseguidos son contraproducentes para el enunciador: ser funado a través de una ACTIVIDAD concreta como es una manifestación pacífica. Por último, se deducen NORMAS Y VALORES vinculados al respeto de los derechos laborales y la dignidad del trabajador.

En el Ejemplo 3 se establece una POLARIZACIÓN entre el pueblo, como referente simbólico que recibe la ayuda/salvación de sus propios miembros (nosotros: compañeros), y el poder que engloba a quienes tienen la capacidad de condenarlo o castigarlo (ellos: la autoridad política y policial). En este 
caso, el texto de convocatoria cumple con los rasgos de enunciación típicos del género: la autorrepresentación positiva la obtiene el pueblo como portavoz de las injusticias que han padecido las personas movilizadas a lo largo del territorio nacional (endogrupo), mientras que la heterorrepresentación negativa se le adjudica implícitamente a quienes han ordenado y perpetrado dichos vejámenes (exogrupo). Este esquema ideológico se complementa con la IDENTIFICACIÓN que abarca a víctimas y victimarios; el primer grupo está conformado por los manifestantes que han caído muertos o heridos en combate, en tanto el segundo grupo está conformado por los carabineros y/o militares responsables de tales crímenes. Los INTERESES se cifran en promover el apoyo mutuo y la resistencia colectiva que se expresan en el activismo callejero y en la lucha social más general, lo cual se cristaliza en la ACTIVIDAD consistente en una marcha masiva que incluye el despliegue de diversos recursos de protesta pacífica (cacerola, pancarta, afiche). A su vez, esta acción está guiada por NORMAS Y VALORES que atañen a la solidaridad del pueblo oprimido y la conmemoración de sus mártires.

En la misma línea, en los Ejemplos 4 y 5 se establece una POLARIZACIÓN entre los capuchas (manifestantes encapuchados), autorrepresentados con atributos de fuerza, valentía y sensibilidad ante las injusticias descritas (endogrupo), y el Estado y sistema opresor, heterorrepresentados como agentes que reprimen y abusan de su poder (exogrupo). En estos casos, los textos de convocatoria circunscriben explícitamente a su enunciatario, ya que, a diferencia de los ejemplos anteriores, se especifica una identidad asociada no solo a la acción de encapucharse, sino de reconocerse como un luchador social que está obligado a esconder su rostro para evitar ser individualizado, perseguido y atacado. Con ello se busca, en alguna medida, reivindicar esta figura frente a la ciudadanía y brindarle legitimidad. Por lo anterior, la IDENTIFICACIÓN se construye a partir de un eje levemente distinto, más próximo al de aliados-enemigos, según el cual el primer grupo queda integrado por cualquier persona, sin distinción de género ni edad, que empatice con sus compañeros caídos, mientras que dentro del segundo grupo se agrega a quienes vulneran la integridad de los manifestantes. Junto con poner a prueba esta defensa, se desprenden otros INTERESES que apuntan a proteger la dignidad de las familias chilenas y a rebelarse contra el sistema, por medio del activismo callejero como fuente de rebeldía y resistencia popular. En concreto, las ACTIVIDADES convocadas corresponden a una marcha familiar de capuchas y a una marcha nocturna de capuchas, las cuales se sustentan en NORMAS Y VALORES referidos al respeto de los derechos humanos, la solidaridad y la unidad.

El Ejemplo 6 es particular en el conjunto, pero se asemeja a otros textos relacionados con la misma convocatoria a participar de la performance feminista "Un violador en tu camino" creada por el colectivo Las Tesis. En este caso, se establece una POLARIZACIÓN entre las mujeres y disidencias sexuales (endogrupo) que denuncian la acción de los violadores (exogrupo). Dada esta confrontación, el esquema ideológico recurre a la IDENTIFICACIÓN de mujeres y disidencias que sufren sistemáticamente la violencia material y simbólica por parte de una sociedad patriarcal que las subyuga y oprime, encarnada en diversas autoridades que accionan la hegemonía masculina en los ámbitos públicos y privados (el Estado, la justicia, la policía). Los INTERESES consisten en visibilizar y contribuir a un proceso de concienciación social en torno a esta situación de violencia estructural normalizada, que denuncia concretamente la impunidad de sus perpetradores. La ACTIVIDAD corresponde a una intervención urbana, inspirada en NORMAS Y VALORES que remiten fundamentalmente a la solidaridad de género.

\subsection{Metáforas conceptuales}

Esta sección reporta el análisis crítico del discurso efectuado a nivel metafórico, cuyos resultados revelan la presencia variable y estratégica de metáforas orientacionales, ontológicas y estructurales. 
Valiéndose de estos tres tipos de metáforas, los textos de convocatoria a jornadas de protesta aportan información con respecto a ciertas formas de aprehender fenómenos abstractos (dominio de destino), tales como: la toma de conciencia sobre las desigualdades y las injusticias sociales, la necesidad de denunciar esta inconformidad, responsabilizar a sus causantes y llamar a la acción, el poder de las movilizaciones como motor para la transformación de la sociedad, etc., a partir de la estructura de conocimiento que subyace a fenómenos más cercanos a nuestra experiencia cotidiana (dominio fuente), tales como: despertarse, mirar, alimentarse, hablar, caminar, etc.

A grandes rasgos, la utilización de metáforas orientacionales recurre a las direcciones arriba/abajo para representar modos de polarización asociados a clases sociales (ricos y pobres, respectivamente), así como a actitudes que se vinculan a estos grupos en oposición (valentía/cobardía, conciencia/inconsciencia, etc.). Adicionalmente, el uso de metáforas ontológicas remite al campo visual y al espacio urbano visible para dar sentido a las acciones mentales (entender, conocer, etc.) de los manifestantes, las cuales se sirven de componentes físicos y materiales (ojos, paredes, etc.) para concretarse. Por último, las metáforas estructurales se emplean para aludir a conceptos y estados de cambio que guían las movilizaciones (defender el país, conquistar derechos ciudadanos, etc.), los cuales se sintetizan por medio de otros conceptos u objetos familiares (alimentos, mercancías, etc.).

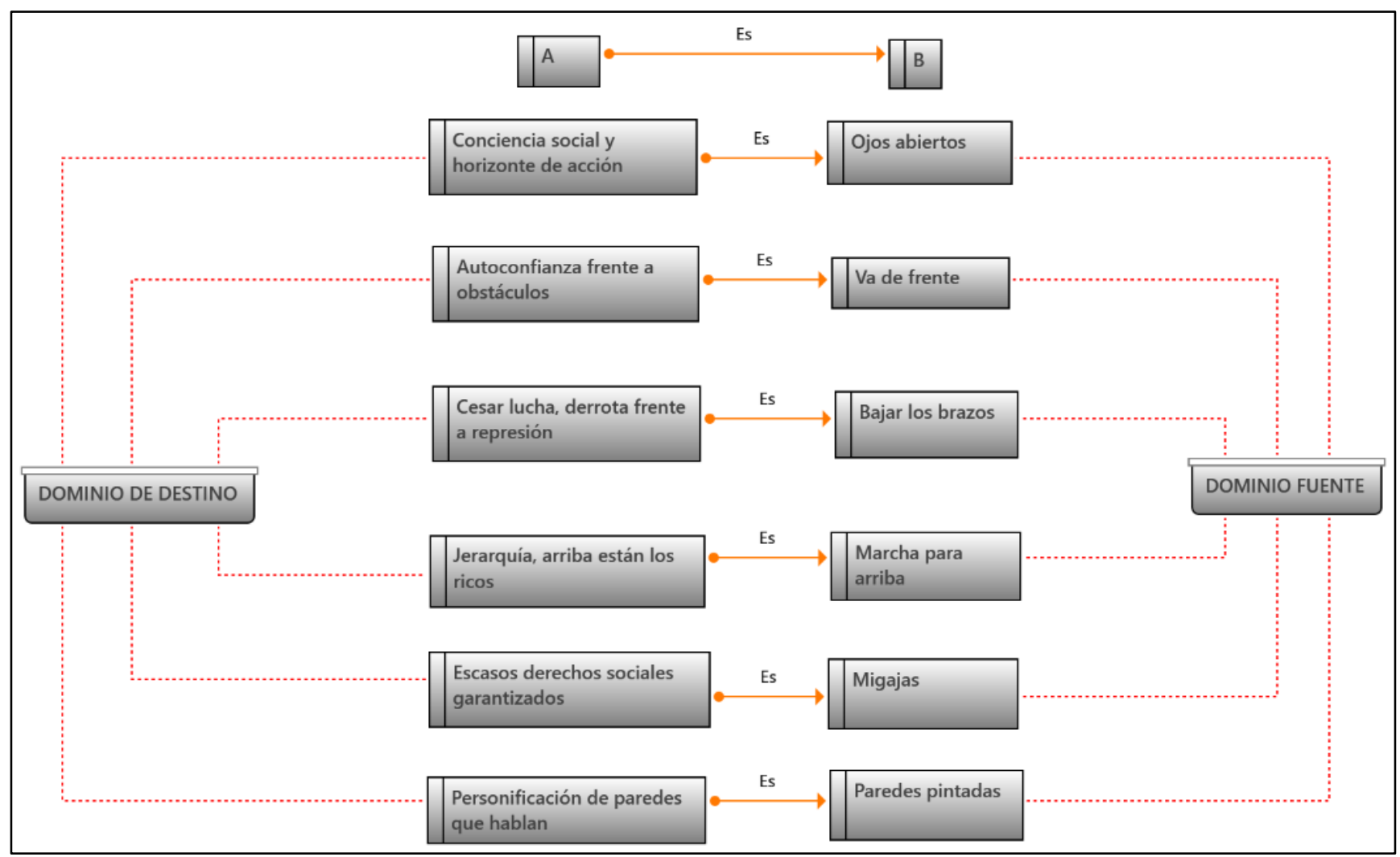

Figura 2: Dominios de metáforas conceptuales

Fuente: Elaboración propia

La Figura 2 muestra un resumen de los dominios de destino (A) y los dominios fuente (B) encontrados en un conjunto acotado de ejemplos. En la columna izquierda aparecen los fenómenos abstractos en virtud de los cuales se construyen implícitamente estos dominios de destino que, según se aprecia en la columna derecha, se correlacionan con los dominios fuente de donde derivan las expresiones lingüísticas que los refieren o simbolizan. 
Las publicaciones seleccionadas para ilustrar este análisis se muestran a continuación:

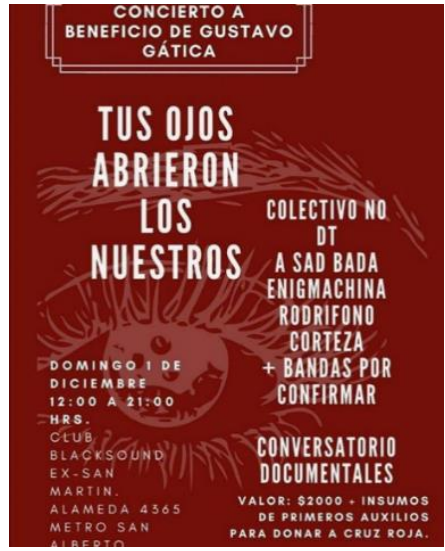

Ejemplo 7: Tus ojos

Fuente: @capucha_informa

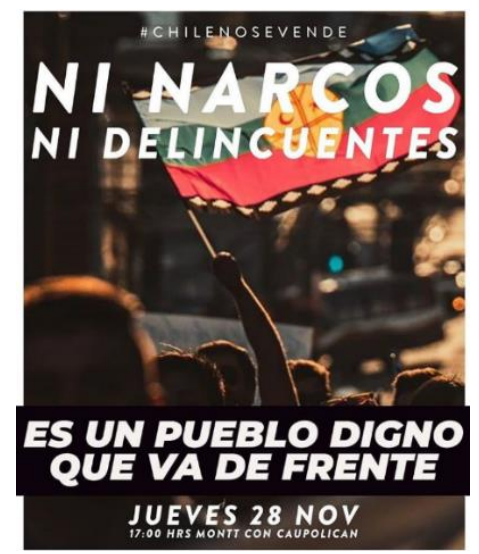

Ejemplo 10: De frente

Fuente: @ capucha_informa

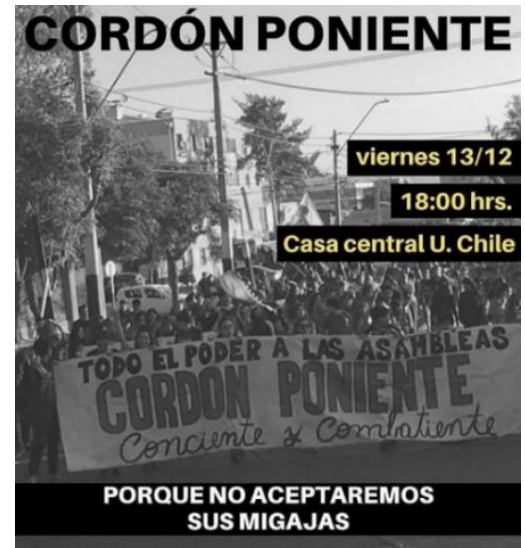

Ejemplo 8: Migajas

Fuente: @ capucha_informa

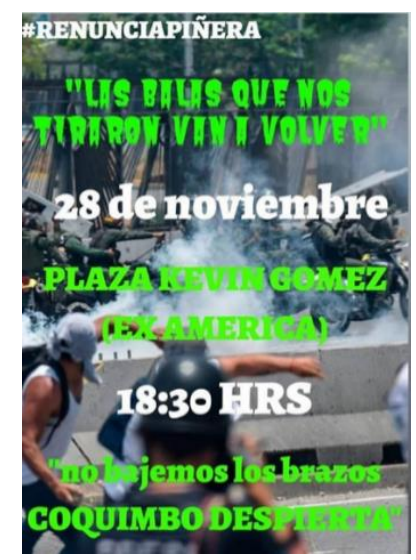

Ejemplo 11: Los brazos

Fuente: @capucha_informa

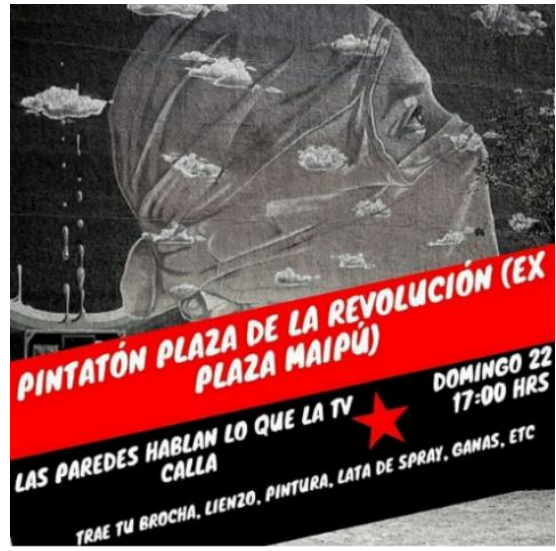

Ejemplo 9: Pintatón

Fuente: @capucha_informa

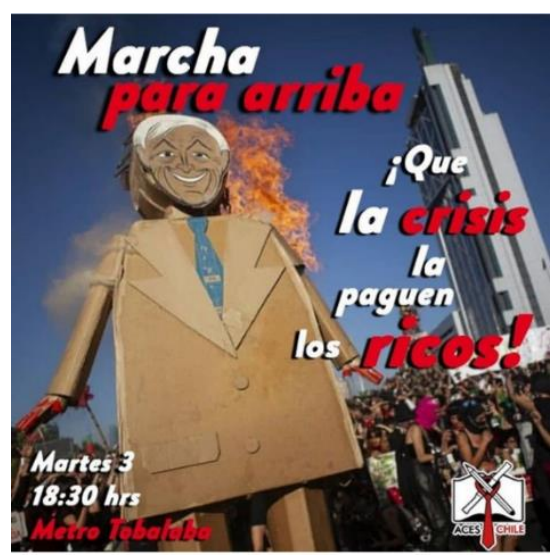

Ejemplo 12: Para arriba

Fuente: @ capucha_informa

El Ejemplo 7 convoca a una serie de actividades a beneficio de Gustavo Gatica, estudiante que perdió la vista por el impacto de perdigones disparados por las fuerzas policiales en medio de una manifestación en Santiago. Debido a la conmoción nacional que ocasionó este hecho, la figura del joven se convirtió rápidamente en un emblema con el cual se comenzaron a asignar cualidades heroicas a los luchadores sociales, en general, y a aquellos heridos por trauma ocular, en particular. En esta publicación, el eslogan "Tus ojos abrieron los nuestros" hace alusión al campo visual que representa la experiencia vital de hacerse consciente de la crisis socio-política que afecta al país, tanto en lo que respecta a las causas estructurales que explican la reproducción de la desigualdad y los abusos de los poderosos, como a la violación de derechos humanos que trae aparejada la represión de la protesta social. Esta concienciación se simboliza a través de los ojos de Gustavo, cuya pérdida conmueve e interpela a quienes aún conservan los suyos a solidarizarse, actuar y rebelarse en su nombre. Así, la metáfora ontológica TOMAR CONCIENCIA ES ABRIR LOS OJOS opera en este y otros casos (ver los Ejemplos 4 y 11) no solo a modo de homenaje, sino como un llamado a la acción que trasciende la comprensión de esta realidad injusta e inhumana.

El Ejemplo 8 es una convocatoria para congregarse en la casa central de la Universidad de Chile, en Santiago, realizada por el cordón poniente que aglutina a las asambleas populares pertenecientes a este sector de la Región Metropolitana. Dicha agrupación, autodenominada "consciente y combatiente", emplaza al gobierno por medio del eslogan "porque no aceptaremos sus migajas", el 
cual se basa en la metáfora estructural LOS DERECHOS SOCIALES SON ALIMENTOS. De este modo, se deduce que el pan, como insumo básico para la subsistencia de las familias, representa uno de los muchos derechos (a la vivienda, a la educación, a la salud, etc.) que han sido acaparados por las elites y que no han sido recibidos íntegramente por la población. De allí que las migajas simbolicen las sobras, esto es, los derechos parciales o restringidos, con los que la gente común y corriente debe conformarse, mientras que otros grupos privilegiados los aprovechan en plenitud.

En el Ejemplo 9 se convoca a una jornada de "pintatón" en las inmediaciones de la renombrada Plaza de la Revolución (ex Plaza Maipú), situada en una comuna del sector poniente de la capital. Esta actividad consiste en pintar las paredes aledañas bajo la consigna "Las paredes hablan lo que la TV calla", con la cual se configura una personificación que, a su vez, corresponde a la extensión de una metáfora ontológica, en tanto permite entender determinados fenómenos con base en motivaciones, intenciones y acciones propiamente humanas que son asignadas a entidades inanimadas. Las paredes, en este sentido, amplifican las voces de los manifestantes materializando críticas y denuncias que no tienen cabida en los medios de comunicación tradicionales; son contenedoras de realidades que los discursos oficiales omiten convenientemente para no responsabilizar a las autoridades en quienes recaen estas acusaciones.

El Ejemplo 10 convoca a una concentración en el centro de Santiago mediante el eslogan "Ni narcos ni delincuentes, es un pueblo digno que va de frente" y el hashtag "ChileNoSeVende". En esta publicación cada frase cumple una función cognitiva distinta. El eslogan involucra una metáfora orientacional que construye dos sentidos de forma simultánea: de un lado, TENER DIGNIDAD ES IR DE FRENTE implica dar la cara literalmente, es decir, no taparla como lo hacen los narcotraficantes u otros criminales cuando cometen delitos, acción que, además, responde a la autorrepresentación positiva del movimiento y su identidad, así como a la deslegitimación de estereotipos con los que a menudo se criminaliza su protesta, apelando a valores alternativos como el coraje, la valentía y la tenacidad; de otro lado, LUCHAR CON DIGNIDAD ES AVANZAR otorga una dirección de futuro a la movilización ciudadana, donde el camino por delante simboliza el horizonte utópico que cristaliza la transformación social. Por su parte, el hashtag implica la metáfora estructural CHILE ES UNA MERCANCÍA, de cuya negación se desprende la necesidad de defender al país de manos de otros delincuentes que se lo han adueñado indebidamente.

El Ejemplo 11 convoca a manifestarse en una de las plazas principales de la ciudad de Coquimbo, utilizando los eslóganes "Las balas que nos tiraron van a volver" y "No bajemos los brazos, Coquimbo despierta". A diferencia de los ejemplos anteriores, esta publicación da cuenta de un posicionamiento más beligerante y ofensivo, el cual se expresa sobre todo en el primer eslogan que remite a la bidireccionalidad de los ataques armados: las balas que se han dirigido desde los policías hacia los manifestantes, tomarán en algún momento una trayectoria inversa. Esta polarización se amplía a través de otras metáforas presentes en el segundo eslogan. En primer lugar, no bajar los brazos remite a la metáfora orientacional RENDIRSE ES ABAJO, donde los brazos funcionan metonímicamente para referir a los cuerpos de los manifestantes (LA PARTE POR EL TODO), y simbolizar tanto la persistencia de la lucha callejera como la obligación de no ceder ante la represión policial. En segundo lugar, la relación metonímica LA CIUDAD POR SUS HABITANTES se conecta con la metáfora ontológica TOMAR CONCIENCIA ES DESPERTAR que, de manera análoga al Ejemplo 6, hace un llamado a mantener un estado de conciencia frente a los atropellos y los abusos de los poderosos.

El Ejemplo 12 convoca a una "Marcha para arriba" que representa territorial y simbólicamente al sector oriente de la Región Metropolitana, en donde reside la clase adinerada del país. Bajo el eslogan "que la crisis la paguen los ricos" no solo se llama a perturbar la normalidad de estas 
comunas (ver también el Ejemplo 1), sino que se relocaliza una disputa por los bienes y espacios que sus habitantes ostentan, en contraposición a la precariedad y marginación a las que se ha sometido al resto de la población. Mientras que la metáfora estructural LA CRISIS ES UNA DEUDA apunta a los costos que debe asumir la ciudadanía producto de la distribución desigual de los derechos sociales, la metáfora orientacional PRIVILEGIADO ES ARRIBA alude a nociones de poder, jerarquía y verticalidad que refuerzan la injusticia y la inequidad imperantes.

\section{Discusión y conclusiones}

De los resultados se concluye que los textos usados para convocar a jornadas de protesta constituyen un género en sí mismo, cuya evolución al interior de comunidades digitales facilita la conformación de comunidades discursivas. Los miembros de estas comunidades, en el cumplimiento de sus finalidades comunicativas, reconstruyen su identidad y aportan a un cambio socio-cognitivo y sociocultural, esencial para concretar las transformaciones estructurales que el movimiento exige (Cárdenas-Neira, 2018).

Las convocatorias publicadas en el Instagram de @capucha_informa activan formas específicas de comprender no solo la protesta, sino el rol que asumen los activistas en el proceso más general que supone alcanzar dichas transformaciones. En concreto, se releva el papel que desempeñan los manifestantes llamados a profundizar la lucha callejera, lo cual se expresa tanto en los esquemas ideológicos que subyacen a los discursos indagados, como en las metáforas conceptuales utilizadas en ellos. En esta línea, los modos de polarización y los tipos de metáforas observados son congruentes y se apoyan mutuamente, por cuanto formulan representaciones antagónicas que se robustecen y extienden en virtud de los atributos que simbolizan a los actores y las acciones implicadas en la lucha social. A partir de estos constructos, los manifestantes posicionan al movimiento como un agente clave de la contienda política, el cual adhiere a ciertos valores y principios reivindicativos que entran en disputa con aquellos valores y principios hegemónicos (Della Porta y Diani, 2011).

El análisis de estos discursos resistentes desvela sistemáticamente las lógicas de los discursos dominantes, ya sea al nivel de la estructura política propiamente tal (el Estado, sus aparatos represores, etc.), y su estructura económica subyacente (la fábrica, los cuicos zorrones, los de arriba, etc.), como al nivel valorativo en razón del cual se enjuicia a los responsables de reproducir y perpetuar tales estructuras (no comparten privilegios, dan migajas, criminalizan, violan, etc.). Estas distinciones se hacen evidentes en las estrategias discursivas empleadas en la elaboración y difusión de los ejemplos que hemos relevado, cuya efectividad radica no solo en el número de participantes que reúnen las convocatorias, sino en cómo se enmarca continuamente una manera de entender y afrontar la crisis socio-política que atraviesa el país.

Los resultados expuestos se desprenden de un estudio piloto que es necesario ampliar y complementar con otras muestras del corpus. Ahora bien, este ejercicio analítico permite dar cuenta preliminarmente del potencial impacto socio-cognitivo que persiguen las estrategias discursivas desplegadas a nivel ideológico y metafórico. Se trata de estrategias que emergen en un estadio inicial del movimiento social, donde es prioritario enmarcar cuestiones muy básicas (aliados, enemigos, demandas, acciones colectivas, etc.) que aparecen claramente identificadas en los textos examinados. Nuevas investigaciones debiesen ayudar a confirmar o tensionar estos hallazgos. 


\section{Referencias}

Acosta, M. (2020). Activismo feminista en Instagram. El caso de la campaña nacional por el derecho al aborto legal seguro y gratuito en Argentina. Perspectivas de la Comunicación, 13(1), 2946. https://dx.doi.org/10.4067/S0718-48672020000100029

Aladro-Vico, E., y Requeijo-Rey, P. (2020). Discurso, estrategias e interacciones de Vox en su cuenta oficial de Instagram en las elecciones del 28-A. Derecha radical y redes sociales. Revista Latina de Comunicación Social, (77), 203-229. https://doi.org/10.4185/RLCS-2020-1455

Alarcón, M., y Godoy, C. (2020). Convocatoria de protesta del movimiento social en Chile como género discursivo. deSignis, 2(33), 287-298. https://doi.org/10.24215/16696581e487

Ardèvol, E., Martorell, S., y San Cornelio, G. (2021). El mito en las narrativas visuales del activismo medioambiental en Instagram. Comunicar, (68), 59-70. https://doi.org/10.3916/C68-2021-05

Aste, B. (2020). Estallido social en Chile: La persistencia de la Constitución neoliberal como problema. DPCE Online, $\quad 42(1), \quad 3-19$. http://www.dpceonline.it/index.php/dpceonline/article/view/885

Bajtín, M. (2005). Estética de la creación verbal. Siglo XXI.

Bennett, W., \& Segerberg, A. (2012). The logic of connective action. Information, Communication \& Society, 15(5), 739-768. https://doi.org/10.1080/1369118X.2012.670661

Bennett, W., \& Segerberg, A. (2016). Communication in movements. In D. Della Porta \& M. Diani (Eds.), The Oxford Handbook of Social Movements (pp. 367-382). Oxford University Press. https://doi.org/10.1093/oxfordhb/9780199678402.013.39

Calsamiglia, H., y Tusón, A. (2019). Las cosas del decir. Manual de análisis del discurso (3 edición). Ariel Letras.

Cárcamo, B. (2018). El análisis del discurso multimodal: Una comparación de propuestas metodológicas. Forma y Función, 31(2), 145-174. https://doi.org/10.15446/fyf.v31n2.7466o

Cárdenas-Neira, C. (2018). Discurso de protesta y redes sociales. Análisis de las prácticas discursivas activistas producidas en la comunidad de Facebook Universitario Informado durante las movilizaciones estudiantiles en Chile (2011-2013) [Tesis doctoral, Universidad Pompeu Fabra]. E-Repositori UPF. https://repositori.upf.edu/handle/10230/36188

Cárdenas-Neira, C. y Pérez-Arredondo, C. (2021). Prácticas discursivas insurgentes y ocupación de espacios urbanos. Análisis de los paisajes semióticos creados en dos ciudades de Chile durante la revuelta social (2019-2020). Bulletin of Spanish Studies. https://doi.org/10.1080/14753820.2021.1961458

Castells, M. (2009). Comunicación y poder. Alianza.

Castells, M. (2012). Redes de indignación y esperanza. Alianza. 
Córdoba-Hernández, A. (2020). Hacia una individualización de la política en redes. Palabra Clave, 23(2), e2321. https://doi.org/10.5294/pacla.2020.23.2.1

Cuadra, A. (2020). Protesta social en Chile, 2019-2020: Fracaso de un modelo económico. Textos y Contextos, (20), 38-50.

Della Porta, D., y Diani, M (2011). Los movimientos sociales. CIS.

Della Porta, D., \& Pavan, E. (2018). The nexus between media, communication and social movements: Looking back and the way forward. In G. Meikle (Ed.), The Routledge Companion to Media and Activism (pp. 29-38). Routledge.

Fernández, A. (2019). Artivismo y co-creación: La comunicación digital en la huelga feminista del 8M. Dígitos, Revista de Comunicación Digital, (5), 56-74. http://dx.doi.org/10.7203/rd.v0i5.142

Figuereo-Benítez, J. C., González-Quiñones, F., y Machin-Mastromatteo, J. D. (2021). Instagram como objeto de estudio en investigaciones recientes. Una revisión de literatura con enfoque en revistas científicas. Ámbitos. Revista Internacional de Comunicación, (53), 9-23. https://dx.doi.org/10.12795/Ambitos.2021.i53.01

Franco, T. C., y Da Silva, M. R. (2020). Cosmofagia y net-activismo indígena brasileño, durante la pandemia de Covid-19. Chasqui: Revista Latinoamericana de Comunicación, (145), 181-196. https://doi.org/10.16921/chasqui.v1i145.4346

Gerbaudo, P., \& Treré, E. (2015). In search of the 'we' of social media activism. Information, Communication \& Society, 18(8), 865-871. https://doi.org/10.1080/1369118X.2015.1043319

Gómez, M. L., Simioni, L., y Traktman, N. (2021). Hasta transformarlo todo Ciberactivismo en Instagram Estudio de casos [Tesis de grado, Universidad Nacional de Córdoba]. Repositorio digital UNC. https://rdu.unc.edu.ar/handle/11086/18263

Güell, P. (2019). El estallido social en Chile: Piezas para un rompecabezas. Mensaje, 68(685), 1-15.

Herrera, R., y Codina L. (2015). Redes sociales visuales: Caracterización, componentes y posibilidades para el SEO de sitios intensivos en contenidos. Cuadernos de documentación multimedia, 26, 3-24. https://doi.org/10.5209/rev_CDMU.2015.v6.50627

Kövecses, Z. (2010). Metaphor. A practical introduction. Oxford University Press.

Kress, G. (2010). Multimodality: A social semiotic approach to contemporary communication. Routledge.

Lakoff, G., y Johnson, M. (1986). Metáforas de la vida cotidiana. Cátedra.

Lalancette, M., \& Raynauld, V. (2017). The power of political image: Justin Trudeau, Instagram, and celebrity politics. American Behavioral Scientist, 63(7), 888924. https://www.doi.org/10.1177/0002764217744838

Lizcano, E. (2002). La metáfora como analizador social. Empiria. Revista de Metodología de Ciencias Sociales, 2, 29-60. https://doi.org/10.5944/empiria.2.1999.709 
Marcos-García, S. (2018). Las redes sociales como herramienta de la comunicación política. Usos políticos y ciudadanos de Twitter e Instagram [Tesis doctoral, Universitat Jaume I]. Tesis Doctorals en Xarxa. https://www.tdx.cat/handle/10803/662817\#page=1

Marcos-García, S., Viounnikoff-Benet, N., y Casero-Ripollés, A. (2020). Què hi ha en un like? Continguts polítics en Facebook i Instagram en les eleccions autonòmiques valencianes de 2019. Debats. Revista de Cultura, Poder $i$ Societat, 134(1), 91-116. https://doi.org/10.28939/iam.debats.134-1.6

Martín Menéndez, S. (2000). Estrategias discursivas: Principio metodológico para el análisis pragmático del discurso. En J. J de Bustos, P. Charaudeau, P. Bustos, J. L. Girón, S. Iglesias y C. López (Coords.), Lengua, discurso, texto (vol. I, pp. 926-945). Visor.

Martín Menéndez, S. (2012). Multimodalidad y estrategias discursivas: Un abordaje metodológico. Revista Latinoamericana de Estudios del Discurso, 12(1), 57-73.

Muñoz, C. L. \& Towner, T. L. (2017). The image is the message: Instagram marketing and the 2016 presidential primary season. Journal of Political Marketing, 16(3-4), 290318. https://www.doi.org/10.1080/15377857.2017.1334254

Parodi, G. (2010). Lingüística de corpus: De la teoría a la empiria. Iberoamericana Vervuert.

Pont Sorribes, C. (2020). Introducción. En C. Pont Sorribes y A. Gutiérrez-Rubí (Eds.), Instagram en la estrategia de construcción de liderazgo político (pp. 11-21). Gedisa.

Quevedo-Redondo, R., \& Portalés-Oliva, M. (2017). Image and political communication on Instagram. Celebrification of the candidates to the presidency of the Government. El Profesional de la Informacion, 26(5), 916-927. https://doi.org/10.3145/epi.2017.sep.13

Sal Paz, J., y Maldonado, S. (2009). Estrategias discursivas: un abordaje terminológico. Espéculo: Revista de Estudios Literarios, 43, 1-27. https://ri.conicet.gov.ar/handle/11336/78060

Sampietro, A., \& Sánchez-Castillo, S. (2020). Building a political image on Instagram: A study of the personal profile of Santiago Abascal (Vox) in 2018. Communication \& Society, 33(1), 169184. https://doi.org/10.15581/003.33.1.169-184

Scolari, C. (2008). Hipermediaciones. Elementos para una teoría de la comunicación digital interactiva. Gedisa.

Selva-Ruiz, D., y Caro-Castaño, L. (2017). Uso de Instagram como medio de comunicación política por parte de los diputados españoles: La estratregia de humanizacion en la "vieja" y "nueva" política. Profesional de la Información, 26(5), 903-915. https://doi.org/10.3145/epi.2017.sep.12

Slimovich, A. (2019). La mediatización contemporánea de la política en Instagram. Un análisis desde la circulación hipermediática de los discursos de los candidatos argentinos. Revista Sociedad, (39), 31-45. 
Somma, N. M., Bargsted, M., Disi Pavlic, R., \& Medel, R. M. (2020a). No water in the oasis: the Chilean spring of 2019-2020. Social Movement Studies. Advance online publication. https://doi.org/10.1080/14742837.2020.1727737

Somma, N., Bargsted, M., \& Sánchez, F. (2020b). Protest issues and political inequality in Latin America. American Behavioral Scientist, 64(9), 1299-1323. https://doi.org/10.1177/0002764220941233

Tilly, Ch., y Wood, L. (2009). Los movimientos sociales, 1768-2008. Desde sus orígenes a Facebook. Crítica.

Tilly, Ch. (1979). Social movements and national politics. Working paper, (197), 1-30. https://deepblue.lib.umich.edu/bitstream/handle/2027.42/50971/197.pdf?sequence=1

Van Dijk, T. (2016a). Estudios Críticos del Discurso: Un enfoque sociocognitivo. Discurso \& Sociedad, 10(1), 171-196. http://www.dissoc.org/ediciones/v10n01/DS10(1)Van\%20Dijk.pdf

Van Dijk, T. (2016b). Discurso y conocimiento. Una aproximación sociocognitiva. Gedisa.

Van Dijk, T. (2005). Ideología y análisis del discurso. Utopía y Praxis Latinoamericana, 10(29), 936. https://www.redalyc.org/pdf/279/27910292.pdf

Van Dijk, T. (2003). Ideología y discurso. Una introducción multidisciplinaria. Ariel.

Van Dijk, T. (1999). Ideología. Una introducción multidisciplinaria. Gedisa.

We Are Social \& Hootsuite. (2021). Digital report. https://wearesocial.com/digital-2021

Yin, R. K. (2014). Case study research: Design and methods (5th edition). Sage.

\section{AUTORES}

\section{Mauricio Alarcón Silva}

Sociólogo, Magíster en Desarrollo Humano Local y Regional de la Universidad de La Frontera. Candidato a Doctor en Comunicación de la Universidad de La Frontera y de la Universidad Austral de Chile. Becario doctoral, Aagencia Nacional de Investigación y Desarrollo (ANID) Desarrolla su tesis doctoral aborda las estrategias discursivas de convocatoria a jornadas de protesta en el marco de la movilización social en Chile. Áreas de Investigación, Movimientos sociales, Análisis Crítico de Discurso.

m.alarcon11@ufromail.com

Orcid ID: https://orcid.org/0000-0002-7234-0392

ResearchGate: https://www.researchgate.net/profile/Mauricio-Alarcon-5

Scopus ID: https://www.scopus.com/authid/detail.uri?authorId=55801397200

\section{Camila Cárdenas Neira}

Profesora de Lenguaje y Comunicación, Magíster en Comunicación y Doctora en Traducción y Ciencias del Lenguaje. Actualmente se desempeña como académica del Instituto de Comunicación Social de la Universidad Austral de Chile, y en paralelo realiza una estancia de investigación posdoctoral como miembro del Centro en Multilingüismo, Comunicación y Discurso (MIRCo) de la 
RLCS, Revista Latina de Comunicación Social, 79, 127-149

[Investigación] DOI: 10.4185/RLCS-2021-1524| ISSN 1138-5820| Año 2021

Universidad Autónoma de Madrid. Sus áreas de investigación abarcan los Estudios Críticos del Discurso y la Semiótica Social, y se especializa en el análisis de discursos multimodales de protesta en redes sociales.

camila.cardenas@uach.cl

Índice H: 9

Orcid ID: https://orcid.org/0000-0002-1842-7200

Google Scholar: https://scholar.google.cl/citations?user=fHo278gAAAAJ\&hl=es

ResearchGate: https://www.researchgate.net/profile/Camila-Cardenas-Neira

Scopus ID: 56534245100

Academia.edu: https://uam.academia.edu/CamilaC\%C3\%A1rdenasNeira?from=navbar 